\begin{tabular}{|c|c|c|}
\hline $\begin{array}{l}\text { PKS } \\
\text { PUBLIC } \\
\text { KNOLLEDGE } \\
\text { PROJECT }\end{array}$ & $\begin{array}{c}\text { REVISTA DE GEOGRAFIA } \\
\text { (RECIFE) } \\
\text { http://www.revista.uffe.br/revistageografia }\end{array}$ & $\begin{array}{l}\text { OJS } \\
\text { OPEN } \\
\text { JOLYNAL } \\
\text { SYYSTENS }\end{array}$ \\
\hline
\end{tabular}

\title{
DIAGNÓSTICO DE VOÇOROCAS NA ZONA PERIURBANA DE GARANHUNS, AGRESTE MERIDIONAL PERNAMBUCANO
}

\author{
Carlos de Oliveira Bispo ${ }^{1}$, George Pereira de Oliveira ${ }^{2}$, Maria Luísa Gomes da Silva ${ }^{3}$, \\ Angelo Cabral dos Santos ${ }^{4}$, Fabrizio de Luiz Rosito Listo ${ }^{5}$, Osvaldo Girão ${ }^{6}$ \\ ${ }^{1}$ Doutorando em Geografia pela UFPE - Email: bispocarlos93@gmail.com \\ ${ }^{2}$ Mestrando em Geografia pela UFPE - Email: georgegeotec15@gmail.com \\ ${ }^{3}$ Mestranda em Geografia pela UFPE - Email: mluisags19@gmail.com \\ ${ }^{4}$ Mestrando em Geografia pela UFPE - Email: angelocabral.santos@hotmail.com \\ ${ }^{5}$ Docente do Programa de Pós-Graduação em Geografia, UFPE-Email: fabrizio.listo@ufpe.br \\ ${ }^{6}$ Docente do Programa de Pós-Graduação em Geografia,UFPE-Email: osgirao@gmail.com
}

Artigo recebido em 30/12/2017 e aceito em 20/03/2018

\begin{abstract}
RESUMO
No município de Garanhuns, localizado no Agreste Meridional Pernambucano, destacam-se processos morfodinâmicos na paisagem com alta degradação por erosão, com muitas incidências de voçorocamentos incorrendo em prejuízos socioambientais. Diante disso, o presente artigo tem como objetivo elaborar o diagnóstico geoambiental de uma voçoroca na zona periurbana do município de Garanhuns, no Estado de Pernambuco. Como marcos metodológicos realizaram-se atividades de campo para observações e preenchimento de ficha cadastral de voçorocas, atividades em gabinete para confecção de mapeamentos, sistematização e discussão dos dados. Nos resultados, em consonância com os dados coletados em campo e em gabinete, destacase que o processo de expansão urbana espontânea vem acelerando a evolução da voçoroca em estudo, provocando riscos expressivos às estruturas próximas à sua borda, incluindo a rodovia BR-423. Desta forma, a partir da análise geoambiental foi possível definir que apesar das causas naturais em função dos solos e do clima local, ações como a disposição de resíduos sólidos, execução de aterros descompactados e esgotos a céu aberto têm servido como gatilhos para o agravamento dos processos erosivos e consequente gênese e evolução da feição erosiva em questão.
\end{abstract}

Palavras-chave: Urbanização; Ação antrópica; Erosão.

\section{DIAGNOSIS OF GULLY EROSION IN THE PERIURBAN ZONE OF GARANHUNS, DRYLANDS OF PERNAMBUCO}

\begin{abstract}
In the municipality of Garanhuns, located in Drylands of Pernambuco, we highlight morphodynamic processes in the landscape with high degradation by erosion, with many incidences of gullies erosions incurring socioenvironmental losses. Aiming at this, this article aims to elaborate the geoenvironmental diagnosis of a gully in the periurban zone of the municipality of Garanhuns, in the State of Pernambuco. As methodological milestones field activities were carried out for observations and completion of cadastral records of gullies erosion, activities in the office for the preparation of mappings, systematization and discussion of the data. In the results, in agreement with the data collected in the field and in the study, it is highlighted that the process of spontaneous urban expansion has accelerated the evolution of the gully in study, causing significant risks to the structures near its edge, including the BR-423 highway. From the geoenvironmental analysis, it was possible to define that, despite the natural causes due to the soil and the local climate, actions such as the disposal of solid waste, the execution of decompressed landfills and open air sewage have served as inputs for the aggravation of erosive processes and consequent genesis and evolution of the erosive feature in question.
\end{abstract}

Keywords: Urbanization; Anthropogenic action; Erosion. 


\section{INTRODUÇÃO}

Os processos erosivos responsáveis pela formação de voçorocas têm sido recorrentemente avaliados na análise geomorfológica relativa às dinâmicas processuais. Isso decorre de seus diversos impactos adversos, como a perda de terras agricultáveis, comprometimento do acesso a recursos hídricos e a danificação de infraestruturas urbanas, como estradas e pontes (VALENTIN et al., 2005; CARVALHO JÚNIOR et al., 2010).

Embora as feições erosivas sejam decorrentes de um processo natural, cujos fatores causais se relacionam às características pedológicas, litológicas, topográficas, regime da precipitação e cobertura vegetal (LE ROUX; SUMMER, 2012), a estrutura e a intensidade das formas de uso e cobertura da terra têm uma significativa influência sobre a frequência e a magnitude do escoamento superficial (DOTTERWEICH et al., 2012). Isso, consequentemente, impacta em taxas de erosão do solo e favorece a formação de voçorocas, sendo um problema crítico para áreas destinadas a agricultura e zonas de expansão urbana.

O processo de voçorocamento é, fortemente, influenciado pelas sociedades humanas, havendo indícios de seu agravamento devido a práticas inadequadas de manejo dos solos, por exemplo (DOTTERWEICH et al., 2012). Mesmo em áreas onde as atividades antrópicas não deram origem as feições erosivas, as pressões antropogênicas são um dos principais fatores de evolução das incisões erosivas, na medida em que o ser humano modifica e altera a paisagem ao longo do tempo (CASTILLO, GÓMEZ, 2016).

No estado de Pernambuco, caracterizado por um diversificado mosaico/contraste de paisagens, desde depressões semiáridas a encostas e cimeiras úmidas/semiúmidas de planaltos, alguns estudos vêm atestando a suscetibilidade natural de determinadas áreas para o voçorocamento (OLIVEIRA et al., 2007; FERREIRA, 2008; AZAMBUJA; CORRÊA, 2015).

Encostas úmidas e semiúmidas situadas a barlavento do Planalto da Borborema, a exemplo da qual se localiza o município de Garanhuns, no Agreste Meridional Pernambucano, é um importante recorte escalar para se entender as interrelações entre evolução de voçorocas e formas de uso e cobertura da terra. Os maiores índices de pluviometria e umidade relacionados aos climas predominantes ao longo do Quaternário favoreceram o desenvolvimento de solos espessos. Com a ocorrência de oscilações climáticas cíclicas desde o Pleistoceno, houve uma considerável retomada erosiva atestada pela existência de paleovoçorocas em diversos setores da paisagem (AZAMBUJA; CORREAA, 2015; LIMA; CORRÊA, 2016). 
Apesar da persistência de um clima subúmido em tempos atuais, muitas paleofeições de incisão estão sendo redinamizadas; não podendo os elementos climáticos por si só explicar essa nova retomada erosiva (AZAMBUJA; CORRÊA, 2015). Dessa forma, o homem e as suas atuais formas conflitantes de uso e cobertura da terra vêm sendo apontados como um dos principais responsáveis pela reativação de paleovoçorocas em Garanhuns, sobretudo nas áreas de expansão urbana, onde atividades agrícolas e a edificação de novas construções coexistem (AZAMBUJA; CORRÊA, 2015). Assim, este trabalho tem por objetivo o diagnóstico geomorfológico de uma voçoroca na zona periurbana do município de Garanhuns, a partir da abordagem de fichas de campo e sobreposição, em ambiente SIG (Sistemas de Informação Geográfica), dos limites da feição erosiva às diferentes classes de uso e cobertura da terra; declividades e seu zoneamento ambiental.

\section{ÁREA DE ESTUDO}

A zona periurbana de Garanhuns, localizada no agreste meridional pernambucano, destaca-se pelos processos erosivos intensos (voçorocamentos), diante da ação dos agentes de degradação e de desestabilização dos solos, devido a sua formação geológica-geomorfológica (Figura 1). É também associada à sua expansão urbana espontânea e, consequentemente, a um uso da terra desprovido de um adequado planejamento urbano no qual diversas moradias convivem com o risco a processos erosivos (Figura 1).

Dentre as várias voçorocas presentes na zona periurbana de Garanhuns, foi selecionada uma que se encontra à margem norte da BR-423 (Figura 2). A escolha desta voçoroca se deu em virtude da mesma se encontrar em uma zona de expansão urbana, onde a coexistência de práticas agrícolas e aumento das áreas edificadas atribuem uma maior complexidade a dinâmica erosiva na área; além da possibilidade de acesso.Trata-se de uma área com atividades antrópicas relacionadas à dinâmica urbana e rural, formas inadequadas de uso e ocupação da terra, como por exemplo, desmatamentos indiscriminados; lançamentos de esgoto e lixo diretamente na voçoroca; entre outros fatores cujo resultado foi a intensificação do processo erosivo e o seu alargamento. 
Figura 1 - Exemplo de áreas de risco a processos erosivos, comumente encontradas em Garanhuns, onde se observa que as ocupações se localizam muito próximas a voçorocas de grandes dimensões.

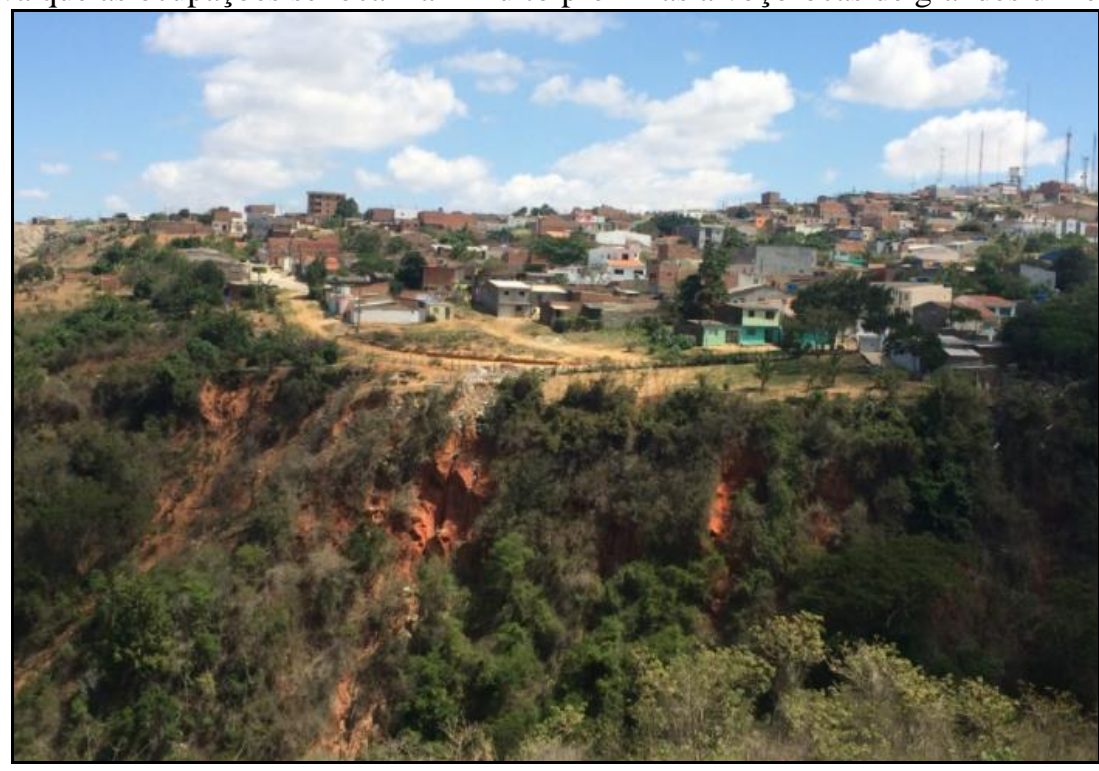

Fonte: Autores.

Figura 2 - Localização da área de estudo (voçoroca selecionada para o dignóstico objeto deste trabalho).

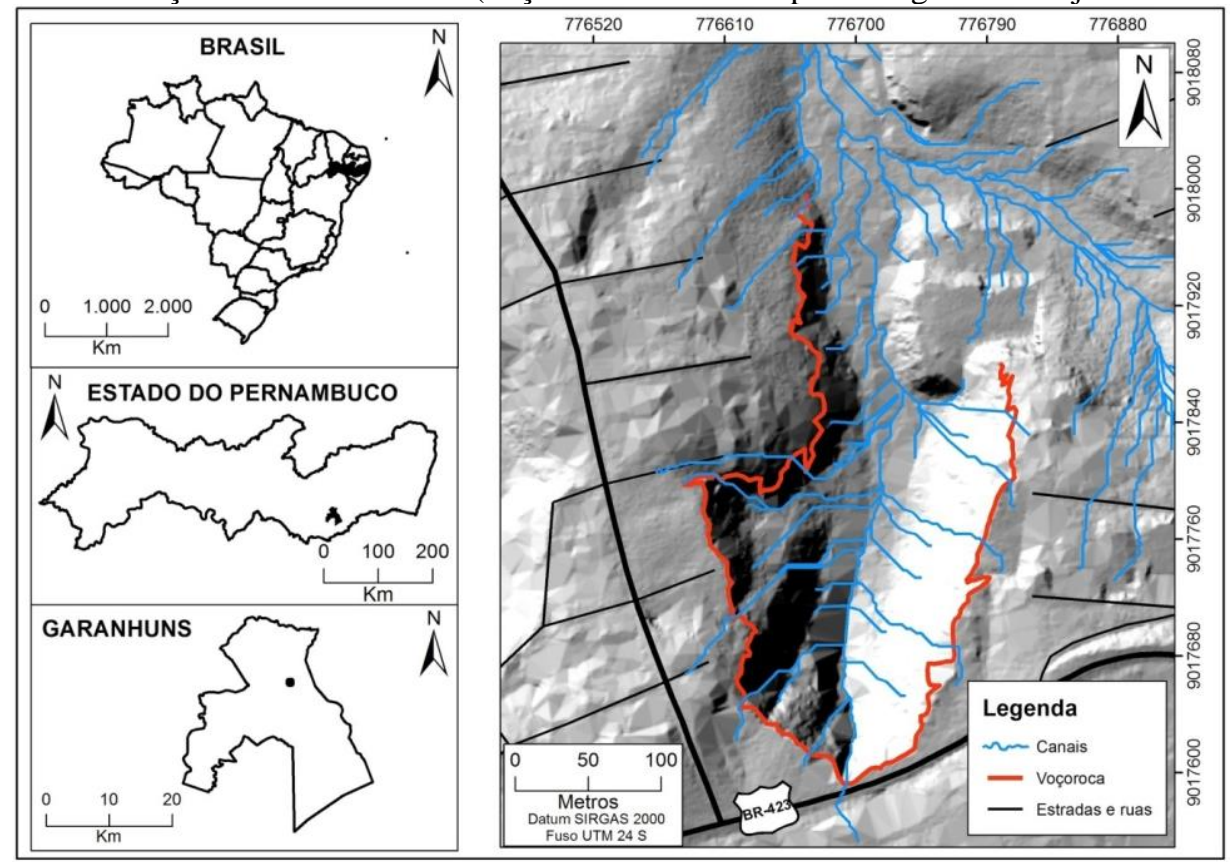

Fonte: Autores.

O município de Garanhuns está inserido no domínio meridional da Província Borborema, caracterizada por um cinturão orogênico meso/neoproterozoico que abarca grande parte da região Nordeste, ao sul do Lineamento Pernambuco. Especificamente para o município de Garanhuns, deve-se considerar duas formações principais: o Complexo Cabrobó, no qual se insere a voçoroca analisada nesse estudo, e o Complexo Belém de São Francisco (AZAMBUJA; CORRÊA, 2015). 
$\mathrm{O}$ primeiro ocorre em direção E-W e é predominante na área centro-sul do sítio urbano, apresentando sequências de rochas metassedimentares (com predominância do quartzito) e metaplutônicas. Já o Complexo Belém de São Francisco ocorre tanto na porção meridional quanto setentrional, circundando o Complexo Cabrobó. Apresenta sequências migmatíticas e ortognaisses tonalítico-granodioríticos e restos de supracrustais do Complexo Cabrobó (CPRM, 2001).

A área estudada está inserida na bacia hidrográfica do rio Mundaú, que possui cerca de $4.120 \mathrm{~km}^{2}$, tendo como principal afluente o Rio Canhoto ao norte. A bacia se estende até o estado de Alagoas onde desemboca na lagoa Mundaú, em Maceió. Localmente falando, os canais de maior influência na cidade são o riacho São Vicente na porção Norte e o riacho Rua Nova ao sul (AZAMBUJA, 2007).

Os solos de Garanhuns provêm basicamente do intemperismo dos quartzitos predominantes in situ e do transporte e da deposição, dando origem a solos alóctones. Os Argissolos e os Latossolos Amarelos são mais frequentes na área, ambos com perfis profundos, sendo os Latossolos constituídos de horizonte B latossólico e os Argissolos com B textural, bastante suscetíveis aos processos erosivos (AZAMBUJA; CORRÊA, 2015).

O clima local é caracterizado por uma considerável sazonalidade, sendo o fator altimetria e o posicionamento de Garanhuns a barlavento do Planalto da Borborema responsáveis pela ocorrência de um clima tropical subúmido. A temperatura média anual é de $20,6{ }^{\circ} \mathrm{C}$, sendo a pluviometria de 874,4 mm/ano (INMET, 2009), condições estas nitidamente diferenciadas dos setores do entorno do município, localizados a sotavento e nas depressões.

Os maiores totais pluviométricos, cujas cotas podem ultrapassar os $100 \mathrm{~mm}$, se concentram em dois períodos: março-abril e maio-junho-julho (AZAMBUJA; CORREAA, 2015). O primeiro reflete a influência da Zona de Convergência Intertropical na precipitação durante o verão, enquanto o segundo se relaciona à atuação nos meses de outono-inverno de Distúrbios Ondulatórios de Leste (DOLs) e à aproximação da Frente Polar Atlântica (FPA) (AZAMBUJA, 2007). Essa caraterística de sazonalidade das chuvas se configura em um fator crítico para a intensificação dos processos erosivos.

Por fim, a compartimentação geomorfológica da área engloba as seguintes unidades: o patamar erosivo com área de cimeira entre $850 \mathrm{~m}$ e $950 \mathrm{~m}$ (incluindo a superfície somital no morro do Magano de $1024 \mathrm{~m}$ ); patamares de dissecação pedimentar a 750/700 m e 650/600 m; um pequeno conjunto de serras alongadas (cristas) de direção ENE/WSW, além de 
modelados de dissecação poli-convexa a $700 \mathrm{~m}$ de altitude ao sul das cristas (AZAMBUJA, 2007).

\section{MATERIAIS E MÉTODOS}

Para o desenvolvimento deste trabalho, visando a análise do processo erosivo, foram adotados três procedimentos metodológicos principais, a saber: (a) diagnóstico da voçoroca por meio do preenchimento de ficha de campo, (b) geração de mapas temáticos em ambiente SIG e (c) mapa de zoneamento ambiental da voçoroca e de seu entorno.

\section{Diagnóstico de voçoroca em campo}

Foi realizado um cadastro da voçoroca, visando o seu diagnóstico e uma avaliação qualitativa e quantitativa da incisão erosiva, a partir de uma ficha de campo (Quadro 1), elaborada por Listo (2017), baseada nos trabalhos de Macedo et al. (2004) e Guerra (2005). Nesta ficha, foram observados e preenchidos os dados de localização da voçoroca (ex. coordenadas e acesso); mensuração de sua geometria/morfometria (comprimento, profundidade e largura média e volume de material erodido) para estimar a dimensão e o grau de evolução da voçoroca, utilizando-se trenas analógicas e digitais (Quadro 1). De posse dos dados referentes a geometria da voçoroca, realizou-se o cálculo da área estimada em $\mathrm{m}^{2}$ (comprimento da feição x largura máxima/2) e do volume estimado de material erodido em $\mathrm{m}^{3}$ (comprimento x largura máxima x profundidade máxima/2).

Para uma análise sistêmica a respeito do diagnóstico da voçoroca foram considerados aspectos relacionados ao seu contexto regional, incluindo as características fisiográficas da área e as características geológicas, geomorfológicas, pedológicas, vegetacionais e de uso da terra (Quadro 1). Assim, foram investigadas as prováveis causas da feição erosiva, alcance do processo em relação ao seu entorno, previsão de evolução e, por fim, o grau de risco da feição erosiva face ao tipo de uso da terra.

Por fim, foram verificados os históricos de acidentes com possíveis vítimas e dano sociais causados pela voçoroca a partir de entrevistas realizadas com moradores locais (Quadro 1). Dessa forma, tal etapa foi essencial para a identificação dos fatores condicionantes do processo, bem como suas consequências ambientais e sociais. Após o trabalho de campo, os dados foram sistematizados em gabinete visando o diagnóstico do processo erosivo. 
Quadro 1 - Exemplo de uma das fichas de cadastro utilizadas em campo para o diagnóstico da feição erosiva.

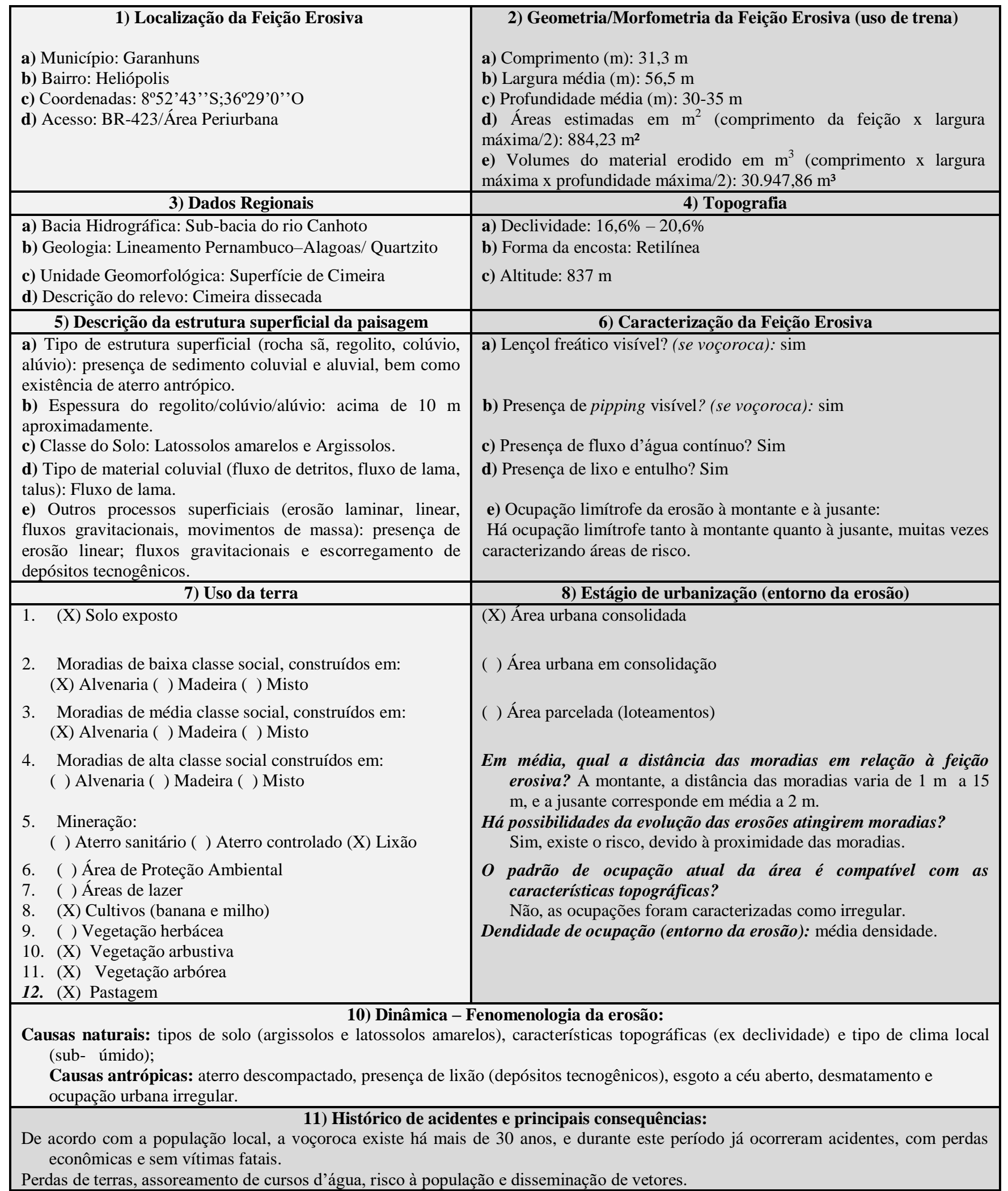

Fonte: Autores (2018). 


\section{Mapeamentos temáticos e Zoneamento Ambiental}

Os dados sistematizados na etapa anterior foram relacionados e discutidos com a elaboração de mapas temáticos (declividade; uso e ocupação da terra e zoneamento ambiental) dentro de um ambiente SIG, com uso do software ArcGIS 10.3.1. Para a geração do mapa de declividade, utilizou-se o Modelo Digital de Terreno (resolução espacial de 1 metro), disponibilizado pelo Projeto Pernambuco Tridimensional - PE3D (Governo de Pernambuco, 2016). A definição das classes de declividade obedeceu aos seguintes níveis de angulação: $0^{\circ}-9,6^{\circ} ; 9,7^{\circ}-16,7^{\circ} ; 16,8^{\circ}>$ tomando por referência Listo e Vieira (2010) e de acordo com a Lei Lehman (Legislação Federal que rege o parcelamento do uso e ocupação da terra de acordo com alguns parâmetros, entre eles a declividade).

As medições de comprimento, de largura e de profundidade da voçoroca calculadas em campo e com o auxílio de imagens de satélite, disponibilizadas pelo Google Earth Pro, foram plotadas sobre um Modelo Tridimensional da feição erosiva analisada. O mesmo foi confeccionado a partir dos dados altimétricos do PE3D no software Global Mapper 18, sendo posteriormente aprimorado em uma ferramenta de edição gráfica, visando melhor acurácia.

Para o mapeamento de uso e cobertura da terra, utilizou-se imagens de satélite do Google Earth Pro dimensionadas na escala de 1:1.200. As mesmas foram exportadas do software e georreferenciadas em ambiente SIG (ArcGIS 10.3.1), sendo reprojetadas de seu datum original WGS 1984 para o Datum SIRGAS 2000, Fuso UTM 24 S. O mapeamento seguiu as recomendações do Manual Técnico de Uso da Terra do Instituto Brasileiro de Geografia e Estatística (IBGE, 2013), cujas classes são distinguidas a partir das características de densidade e de porte da vegetação; além do grau de alteração antrópica (fotointerpretação). Assim, as classes identificadas foram: vegetação arbórea, vegetação arbustiva, áreas de cultivo, solo exposto, depósitos de resíduos sólidos, áreas edificadas e estradas asfaltadas.

A partir das classes de uso e cobertura da terra identificadas, elaborou-se o zoneamento ambiental simplificado da voçoroca e seu entorno. Este teve como fundamentação metodológica a proposta de Costa et al., (2014), cuja base é a dinâmica geoecológica do ambiente analisado, explicitada a partir de seu grau de degradação de qualidade ambiental. Entende-se como degradação da qualidade ambiental as alterações adversas das características naturais do meio ambiente, principalmete relacionadas às modificações na cobertura vegetal, confome a Política Nacional do Meio Ambiente (BRASIL, 1981). O zoneamento permitiu a distinção de três zonas distintas: zonas de uso restrito, zonas de risco e zonas de recuperação (Tabela 1). 
Tabela 1 - Categorias do Zoneamento Ambiental Simplificado.

\begin{tabular}{c|l}
\hline Categorias do zoneamento & \multicolumn{1}{c}{ Características } \\
\hline Zona de Uso Restrito & $\begin{array}{l}\text { Zonas destinadas apenas para atividades de recreação e educacionais, } \\
\text { cuja edificação apenas poderá ser realizada mediante licenciamento } \\
\text { ambiental. }\end{array}$ \\
\hline Zona de Risco & $\begin{array}{l}\text { Zonas onde a degradação ambiental e ocupação irregular acarretaram } \\
\text { em uma suscetibilidade à erosão do solo devido à retirada parcial da } \\
\text { vegetação. }\end{array}$ \\
\hline Zona de Recuperação & $\begin{array}{l}\text { Zonas antropicamente alteradas que apresentam um elevado risco de } \\
\text { erosão em função da ausência da cobertura vegetal. }\end{array}$ \\
\hline
\end{tabular}

Fonte: Adaptado de Costa et al. (2014).

\section{RESULTADOS E DISCUSSÕES}

\section{Diagnóstico da voçoroca e parâmetro declividade}

De acordo com os cálculos levantados em campo, a voçoroca apresentou 377 metros de comprimento, 195 metros de largura e 35 metros de profundidade (Figura 3). Assim, conforme a metodologia utilizada, estima-se que a área da voçoroca possui $73.515 \mathrm{~m}^{2}$, tendo um volume estimado de $1.286 .513 \mathrm{~m}^{3}$ de material erodido; apresentando, portanto, grandes dimensões.

Esta voçoroca se encontra em uma sub-bacia do Rio Canhoto; estruturada sobre o Lineamento Pernambuco-Alagoas em uma superfície de cimeira dissecada com litotipos predominantes de quartzitos. Apresenta formas da encosta majoritariamente retilíneas, altitudes de $837 \mathrm{~m}$ e presença de Latossolos e Argissolos. Há sedimentos coluviais e aluviais (espessuras aproximadamente de $10 \mathrm{~m}$ ), bem como existência de aterro antrópico com a presença de muito lixo e entulho, no qual o lençol freático é vísivel, devido à sua exposição em função do aprofundamento da voçoroca (escoamento superficial e subsuperficial identificado pela presença de pippings). Muitos destes sedimentos podem ter sido originados de fluxos/corridas de lama pretéritos. Além disso, ainda foi verificada a ocorrência de fluxos gravitacionais e escorregamentos de depósitos tecnogênicos, cuja ocupação antrópica, na borda da voçoroca, é intensa.

Com relação à declividade (Figura 4), foi identificado que a voçoroca está praticamente dentro da classe mais elevada $\left(16,8^{\circ}>\right)$; confirmando a maior suscetibilidade desta classe na potencialização dos processos erosivos. Assim, considerando todo o entorno da voçoroca ora analisada, $26,1 \%$ da área total está na classe mais declivosa; $48,1 \%$ na classe mais suave $\left(0^{\circ}-9,6^{\circ}\right)$ e $25,8 \%$ na classe intermediária $\left(9,7^{\circ}-16,7^{\circ}\right)$, conforme a Figura 4. 
As áreas mais declivosas aceleram a erosão com o agravamento da voçoroca, principalmente pelo aumento da velocidade do escoamento superficial da água e do poder erosivo na movimentação de materiais superficiais. Dessa forma, segundo a Lei Federal $n^{\circ}$ 6.766 de 19 de dezembro de 1979 - (Lei Lehmann), os terrenos com declividade igual ou superior a $30 \%\left(\sim 16,8^{\circ}\right)$ não são recomendados para o parcelamento do solo, salvo se atendidas exigências específicas das autoridades competentes; o que muitas vezes não é constatado na paisagem local.

Figura 3 - Bloco diagrama da voçoroca e seu entorno na qual é possível observar as características geométricas da feição erosiva (comprimento, largura e profundidade).

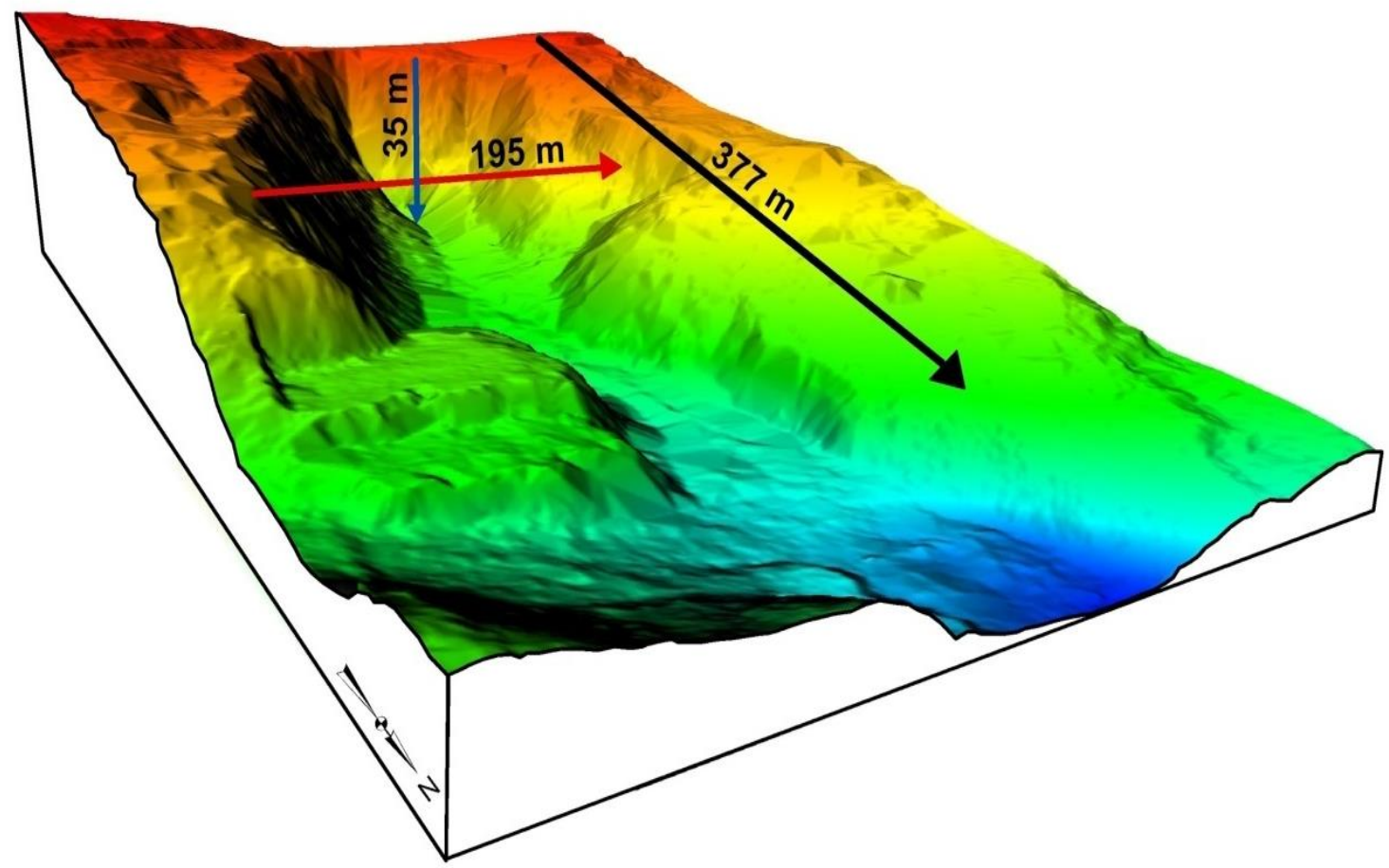

Fonte: Autores. 
Figura 4 - Classes de declividade na voçoroca e no seu entorno.

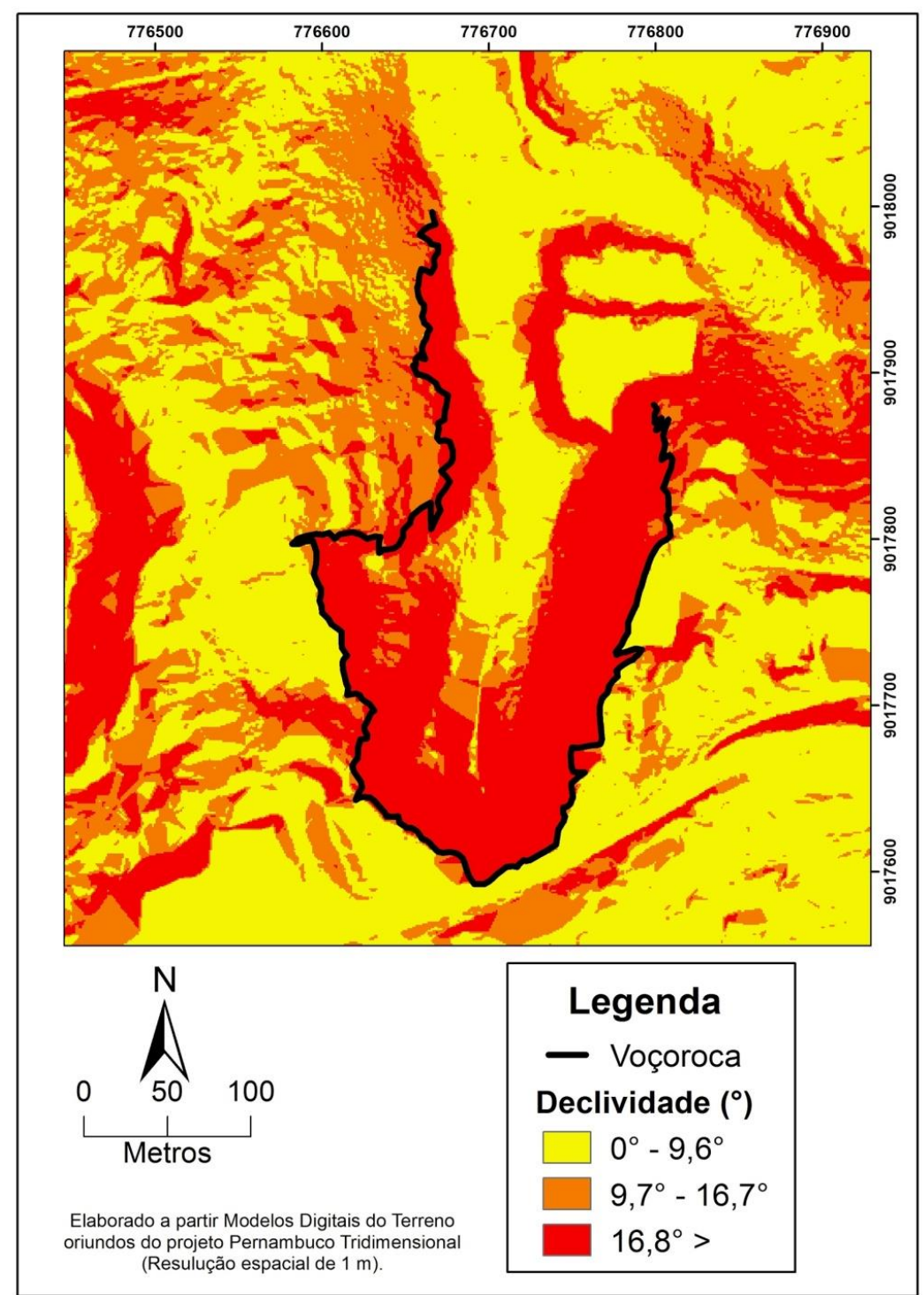

Fonte: Autores.

\section{Uso e Ocupação da Terra}

Com relação ao uso da terra da feição erosiva e o seu entorno (Figura 5), a ocupação antrópica é bastante significativa conforme a Tabela 2, onde 41,9\% da área é composta por áreas edificadas, juntamente com 2,9\% de áreas asfaltadas. Nas áreas edificadas, predominam construções em alvenaria destinadas a moradias de baixa e média classe social, além de galpões comerciais e estruturas voltadas para o lazer e turismo. $\mathrm{O}$ uso da terra na área é também marcado por algumas categorias não adequadas à realidade local, tais como locais para deposição de resíduo sólido (lixão); áreas de cultivo e solo exposto, com uma porcentagem de 4,2\%; $12 \%$ e 3,1\% respectivamente (Figura 5; Tabela 2). 
Nas áreas de cultivo $(3,1 \%)$ foram identificadas culturas de milho e de feijão, que ocorrem intercaladas às zonas de vegetação arbustiva $(25,2 \%)$ onde há também a presença de caatinga rala. Nestas últimas, predominam espécies do gênero Mimosa, que se distribuem pelos setores de maior declividade na voçoroca e áreas mais distantes das áreas edificadas (Figura 5; Tabela 2). Essa característica aponta para um caráter secundário da vegetação, sendo essas zonas trechos em recuperação outrora submetidos a processos de degradação mais intensos. Muitas vezes, essas áreas de vegetação menos fechadas são aproveitadas como áreas de pasto bovino.

Nas áreas onde há uma maior acumulação de água, desenvolveu-se uma vegetação arbórea $(10,7 \%)$, onde espécies da caatinga se contrastam a espécies exóticas, em sua maioria frutíferas, que não se destinam a produção comercial (ex. bananeiras) (Figura 5; Tabela 2). Com relação a este tipo de cultivo, ressalta-se o potencial de intensificação dos processos de erosão do solo, uma vez que a mesma possui em virtude da geometria de suas folhas e caules, um sistema radicular pouco profundo. Assim, sua capacidade de retenção de umidade e o seu peso, contribuem para o chamado efeito alavanca, favorecendo a canalização das águas pluviais e instabilização de encostas (SALES et al., 2006). Dessa forma, favorecem o possível alargamento da voçoroca; considerando que este tipo de plantio deve ser evitado em áreas de relevo íngreme.

Na extremidade a montante da voçoroca, em seu limite com a BR-423, existe um depósito a céu aberto de resíduos sólidos urbanos (lixão), que formam um talude de inclinação considerável, sujeitos à diversas instabilidades (Figura 6). A percolação do chorume pelos resíduos representa um sério risco à qualidade das águas superficiais e subterrâneas como já atestado em outros lixões que preenchem voçorocas (ROCHA, 2006). Ressalta-se também a possibilidade de escorregamentos de resíduos sólidos (depósitos tecnogênicos) frente a eventos espasmódicos de precipitação, levando em consideração a forma instável como os resíduos se agregam.

Destaca-se, ainda, que a distância das moradias da zona de voçorocamento a montante varia entre $1 \mathrm{~m}$ e $15 \mathrm{~m}$, enquanto a jusante esse valor é de somente $2 \mathrm{~m}$, o que induz um risco alto com relação à possibilidade de moradias serem atingidas pela evolução remontante da cabeceira e bordas laterais da voçoroca. Esse grau de risco se justifica pela forma irregular das construções edificadas, não respeitando as características da topografia local; ou seja, há um desacordo entre as características naturais e o planejamento das áreas edificadas. 
Figura 5 - Mapa de uso e ocupação da terra da voçoroca e seu entorno.

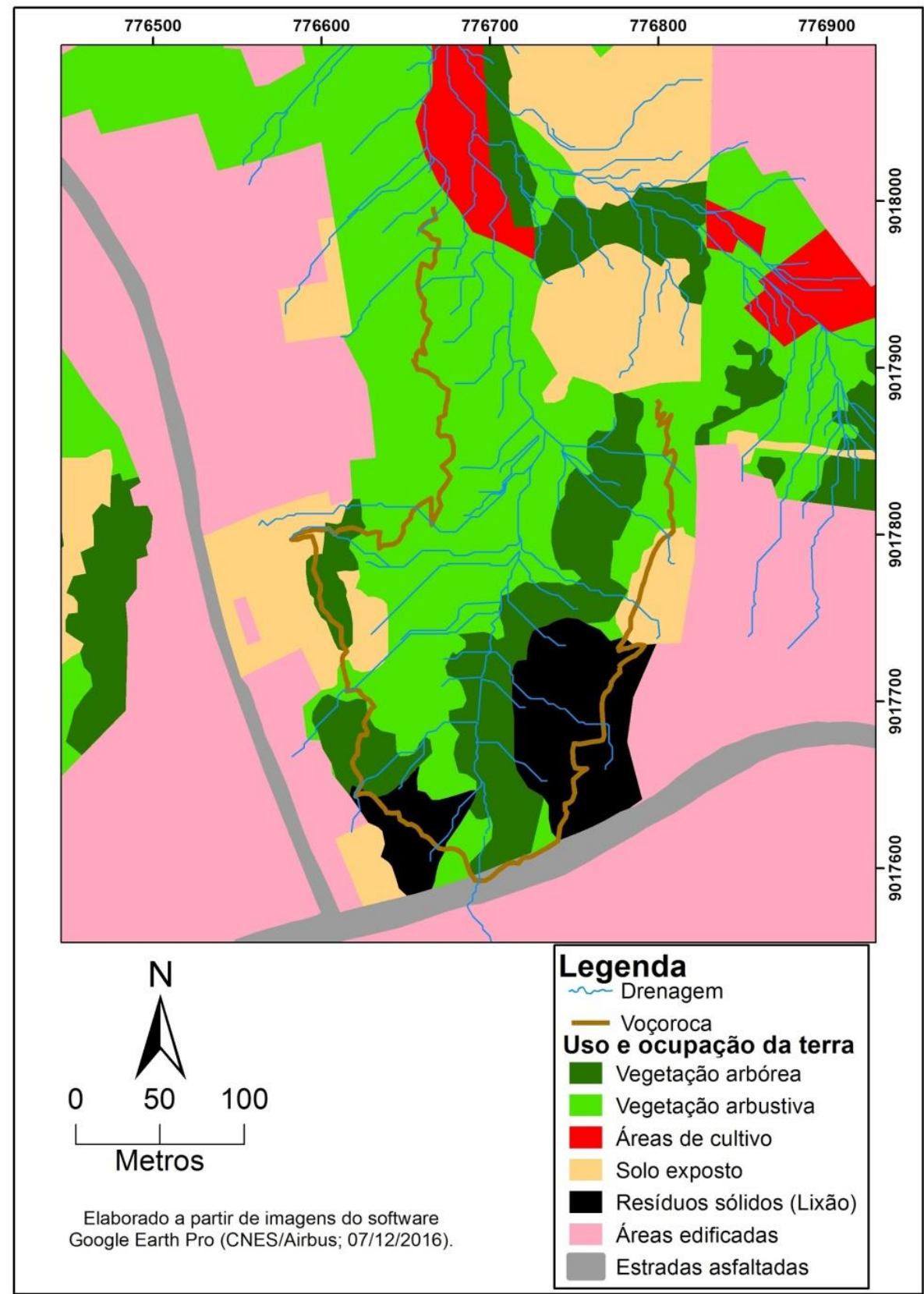

Fonte: Autores.

Tabela 2 - Porcentagens das classes de uso e ocupação da terra da voçoroca e seu entorno.

\begin{tabular}{c|c}
\hline CLASSES DE USO E OCUPAÇÃO DA & PORCENTAGEM (\%) \\
TERRA & \\
\hline VEGETAÇÃO ARBÓREA & 10,7 \\
VEGETAÇÃO ARBUSTIVA & 25,2 \\
ÁREAS DE CULTIVO & 3,1 \\
SOLO EXPOSTO & 12 \\
LIXÃO & 4,2 \\
ÁREAS EDIFICADAS & 41,9 \\
ESTRADAS ASFALTADAS & 2,9 \\
TOTAL & $\mathbf{1 0 0 , 0 0}$ \\
\hline
\end{tabular}

Fonte: Autores. 
Figura 6 - Depósitos de resíduos sólidos na borda da voçoroca (depósitos tecnogênicos).

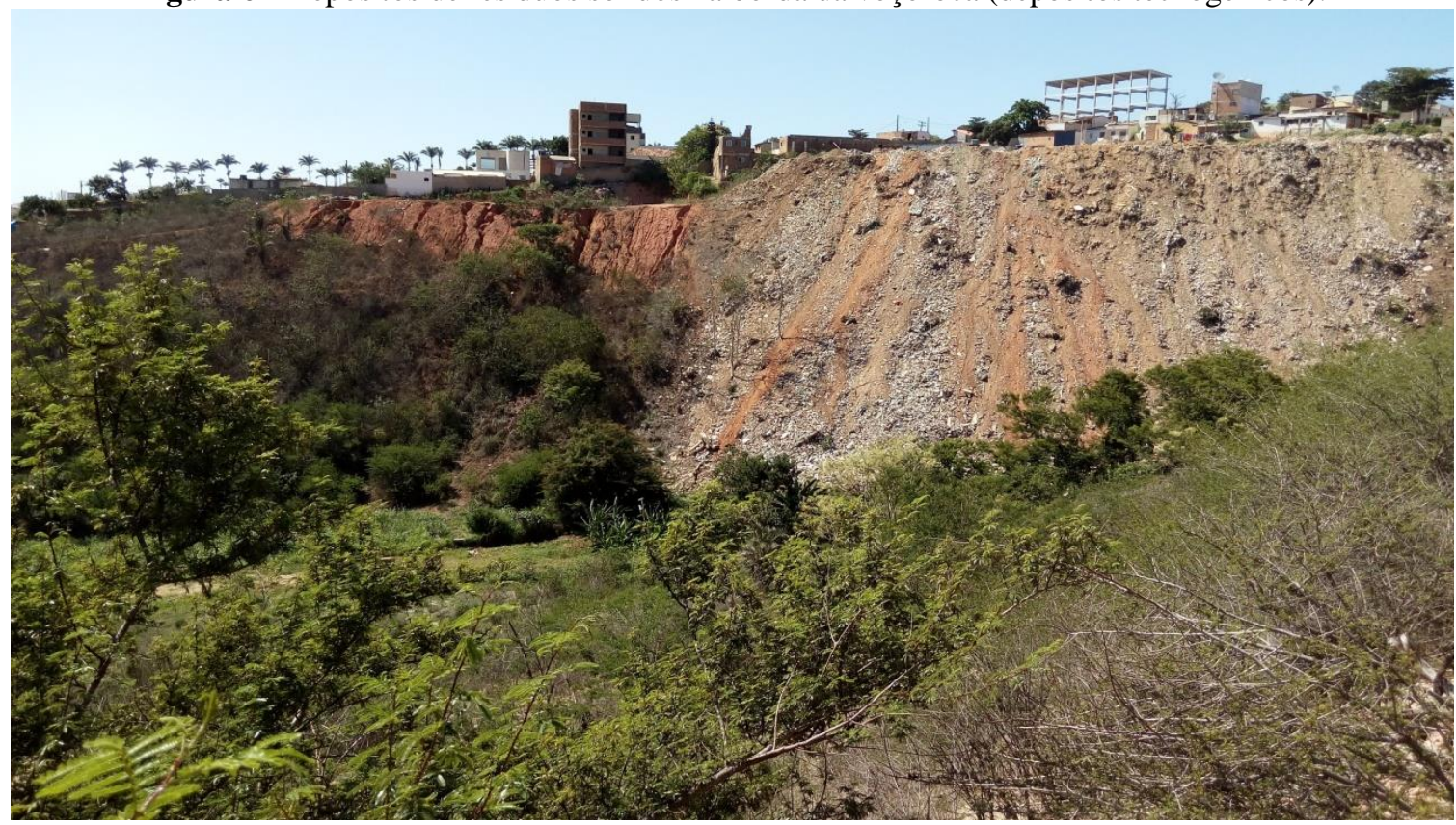

Fonte: Autores.

\section{Zoneamento ambiental simplificado da voçoroca e seu entorno}

As diferentes classes de uso e ocupação da terra, permitiram a elaboração de um zoneamento ambiental simplificado da voçoroca e de seu entorno (Figura 7 e Tabela 3). Neste, foram identificadas três zonas distintas com base em seu estágio de degradação ambiental: zonas de uso restrito, zonas de risco e zonas de recuperação, correspondendo a um percentual de $10,7 \% ; 28,4 \%$ e $16,2 \%$, respectivamente. Destaca-se que as áreas edificadas do perímetro mapeado corresponderam a $44,7 \%$ do total.

As zonas de uso restrito correspondem às áreas onde a vegetação arbórea ainda se mantém, devendo ser explorada de forma planejada (Figura 7). A retirada de árvores deve ser evitada, excetuando-se a isso as espécies exóticas que podem intensificar a erosão do solo, tais como as bananeiras. Nesse caso, deve-se repor a cobertura vegetal com espécies nativas ou espécies que não comprometam de forma decisiva na agregação das partículas do solo.

Os campos de cultivo e as áreas de ocorrência de vegetação arbustiva compõem as zonas de risco (Figura 7). Nessa zona, o estágio de degradação ambiental é considerável, mas não alteraram totalmente a dinâmica geoambiental em virtude de ainda existirem coberturas vegetais, sejam elas naturais, como no caso dos remanescentes de caatinga, ou não, como nas áreas de cultivo. Nesse último caso, devem-se adotar práticas de manejo do solo adequadas às características topográficas e às propriedades físico-químicas locais para se evitar a perda da 
fertilidade natural e instabilidade dos agregados nas coberturas pedológicas, o que pode acarretar no agravamento dos processos erosivos.

As zonas de recuperação são aquelas onde a degradação ambiental atingiu níveis críticos, sendo composta pelas áreas de solo exposto e por depósitos de resíduos sólidos (lixões) (Figura 7). As áreas de solo desnudo, quando se localizam próximas às bordas de avanço da erosão, não devem ser ocupadas, devido seu alto grau de instabilidade. Assim, é necessária a correção dessas áreas, sendo a reintrodução da vegetação, uma medida inicial a ser adotada. Especificamente para os resíduos sólidos, os planos diretores municipais indicam os locais mais adequados para a disposição dos mesmos e, dessa forma, deve-se evitar a utilização da voçoroca para este fim; considerando-se que a área torna-se vulnerável também a proliferação de vetores e transmissão de doenças.

Por fim, as áreas edificadas estão em sua marioria, conforme já mecionado, localizadas em áreas de risco devido à alta possibilidade de evolução da incisão erosiva; necessitando, dessa forma, de medidas estruturais e não estruturais de contenção, como por exemplo, retaludamentos, muros de arrimo, entre outros. 
Figura 7 - Zoneamento ambiental simplificado da voçoroca e seu entorno.

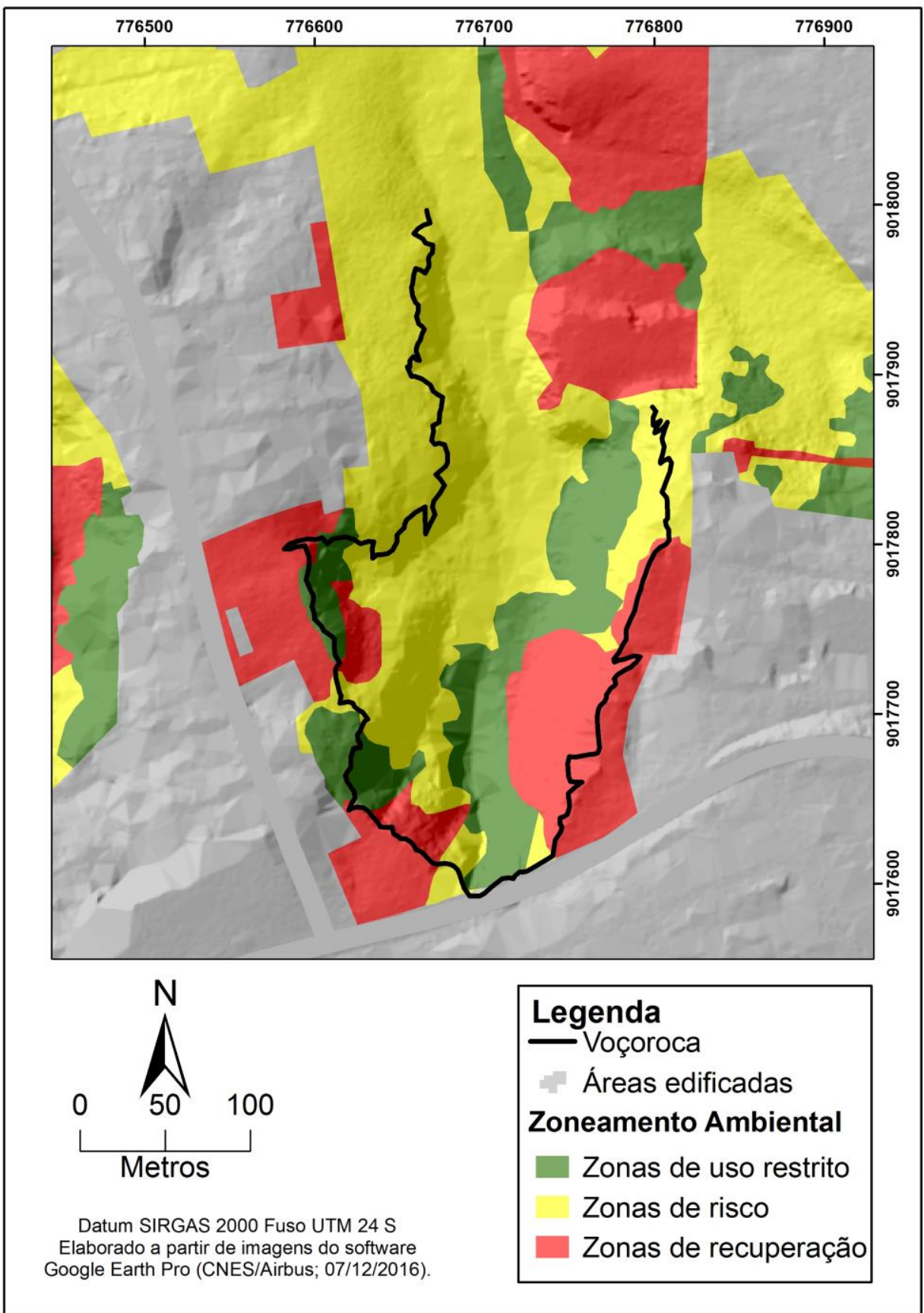

Fonte: Autores.

Tabela 3 - Porcentagens das classes do Zoneamento Ambiental da voçoroca e seu entorno

\begin{tabular}{c|c}
\hline CLASSES DO ZONEAMENTO AMBIENTAL & PORCENTAGEM (\%) \\
\hline ZONAS DE USO RESTRITO & 10,7 \\
ZONAS DE RISCO & 28,4 \\
ZONAS DE RECUPERAÇÃO & 16,2 \\
ÁREAS EDIFICADAS & 44,7 \\
TOTAL & $\mathbf{1 0 0 , 0 0}$ \\
\hline
\end{tabular}

Fonte: Autores. 


\section{CONSIDERAÇÕES FINAIS}

Nota-se no município de Garanhuns processos morfodinâmicos da paisagem, com alta degradação por erosão, representados por voçorocas. Estas por sua vez vêm causando diversos problemas, como perdas de terras, assoreamentos de cursos d'água e riscos à população.

O cadastro da voçoroca realizado ofereceu uma visão sistêmica das principais formas e processos atuantes na feição erosiva. Reforça-se, assim, a necessidade de medidas preventivas, diante da criticidade da degradação do processo erosivo avaliado.

Destaca-se aqui a importância de Modelos Digitais do Terreno de alta resolução (ferramentas de Geotecnologias) associadas às fichas de campo para o dianóstico de processos erosivos; incluindo sua aplicação em outros ambientes, sejam úmidos ou semiáridos. O nível de precisão da escala de MDT's de alta resolução permitiram, portanto, a análise detalhada de diversos parâmetros topográficos, apresentando um elevado potencial para os estudos de Geomorfologia Dinâmica; Geotecnia e de outras áreas voltadas para a problemática geoambiental.

Por fim, o município de Garanhuns passa por um uso da terra que não respeita as limitações impostas por suas características geoambientais e os seus riscos inerentes. Portanto, espera-se que este estudo possa fornecer um diagnóstico mais detalhado da paisagem local do município, oferecendo subsídios para um melhor planejamento que esteja concatenado às diretrizes dos Planos Diretores e de outras legislações em suas diferentes esferas administrativas.

\section{REFERÊNCIAS}

AZAMBUJA, R. N. Análise Geomorfológica em áreas de expansão urbana no município de Garanhuns-PE. 2007. 148 f. Dissertação (Mestrado em Geografia) - DCG, Universidade Federal de Pernambuco, Recife, 2007.

AZAMBUJA, R.N. CORRÊA, A.C.de B. Geomorfologia e áreas de expansão urbana do Município de Garanhuns-PE: uma abordagem espaço temporal dos eventos morfodinâmicos para o planejamento territorial. Revista Geo UERJ, Rio de Janeiro: 2015. pp. 202-233.

BRASIL. Lei $n^{0}$ 6.766, de 19 de dezembro de 1979. Dispõe sobre o Parcelamento do Solo Urbano e dá outras Providências. Disponível em: <http://www.planalto.gov.br/ccivil_03/leis/L6766.htm> Acesso em: 28 jul.de 2017. 
BRASIL. Lei $\mathbf{n}^{\mathbf{0}}$ 6.938, de 31 de agosto de 1981. Dispõe sobre a Política Nacional do Meio Ambiente, seus fins e mecanismos de formulação e aplicação, e dá outras providências. Disponível em: <http://www.planalto.gov.br/ccivil_03/leis/16938.htm>. Acesso em: 28 jul. 2017.

CARVALHO JUNIOR, O.; GUIMARAES, R.; FREITAS, L.; GOMES-LOEBMANN, D.; GOMES, R. A.; MARTINS, E.; MONTGOMERY, D. R. Urbanization impacts upon catchment hydrology and gully development using mutli-temporal digital elevation data analysis. Earth Surf. Process. Landforms, v. 35, n. 5, p. 611-617, 2010.

CASTILLO, C.; GÓMEZ, J. A. A century of gully erosion research: Urgency, complexity and study approaches. Earth-Science Reviews, v. 160, n. 1, p. 300-319, 2016.

COSTA, D. F. S.; GUEDES, J. C. F.; ROCHA, R. M. Estratégia de zoneamento ambiental aplicada à gestão das margens de reservatórios. Geosul, Florianópolis, v. 29, n. 58, p 145-159, 2014.

CPRM - COMPANHIA DE RECURSOS MINERAIS. Governo do Estado de Pernambuco. Geologia e Recursos Minerais do Estado de Pernambuco. Recife: CPRM, 2001.

DOTTERWEICH, M.; RODZIK, J.; ZGŁOBICKI, W.; SCHMITT, A.; SCHMIDTCHEN, G.; BORK, H. High resolution gully erosion and sedimentation processes, and land use changes since the Bronze Age and future trajectories in the Kazimierz Dolny area (Nałęczów Plateau, SE-Poland). Catena, v. 95, n. 1, p. 50-62, 2012.

FERREIRA, R. V. Mapeamento geomorfológico e de processos erosivos da bacia hidrográfica do rio Botafogo - PE utilizando técnicas de geoprocessamento. 2008. $153 \mathrm{f}$. Tese (Doutorado em Geociências) - Centro de Tecnologia e Geociências, Universidade Federal de Pernambuco, Recife, 2008.

GUERRA, A.J.T. Experimentos e monitoramentos em erosão dos solos. Revista do Departamento de Geografia, São Paulo, n. 16, p. 32-37, 2005.

IBGE. Manual técnico de uso da terra. 3. ed. Rio de Janeiro: IBGE, 2013.

INMET. Instituto Nacional de Meteorologia. Normais Climatológicas do Brasil 1961-1990. Organizadores: Andrea Malheiros Ramos, Luiz André Rodrigues dos Santos, Lauro Tadeu Guimarães Fortes. Brasília, DF: INMET, 2009.

LE ROUX, J. J.; SUMMER, P. D. Factors controlling gully development: comparing continuous and discontinuous gullies. Land Degradation \& Development, v. 23, n. 5, p. 440-449, 2012. 
LIMA, E. M.; CORRÊA, A. C. B. Mapeamento geomorfológico como ferramenta de caracterização ambiental do município de Garanhuns-PE. Geosul, Florianópolis, v. 31, n. 62, p. 317-336, 2016.

LISTO, F. L. R.; VIEIRA, B. C. Análise de condicionantes topográficos como subsídio para avaliação de áreas de risco a escorregamentos rasos. Revista de Geografia. Recife: UFPE DCG/NAPA, v. especial VIII SINAGEO, n. 3, Set. 2010.

LISTO, F. L. R. Ficha de campo: cadastro de voçorocas em solos residuais e sedimentos colúvio-aluviais. Programa de Pós-Graduação em Geografia - UFPE. Recife, 2017. Disponível em: <http://professorfabrizioufpe.blogspot.com.br/2017/03/fichas-decampo.html> Acesso em: 11 jun. 2017.

OLIVEIRA, N. M. G. A.; CARVALHO, J. A. R.; SILVA, J. N. Degradação ambiental no bairro dos estados, município de Camaragibe-PE: sistema de voçorocas. Cadernos de Cultura e Ciência, Crato, v. 2, n. 2, p. 1-11, 2007.

ROCHA, L. Disposição de resíduos sólidos numa voçoroca e seus impactos sobre as águas: um estudo de caso em Uberlândia/MG. 2006. 189 f. Dissertação (Mestrado em Engenharia Civil) - Faculdade de Engenharia Civil, Universidade Federal de Uberlândia, Uberlândia, 2006.

SALES, M. M.; CAMAPUM DE CARVALHO, J.; PALMEIRA, E. M. Controle de erosões. In: CAMAPUM DE CARVALHO, J.; SALES, M. M.; SOUZA, N. M.; MELO, M. T. S. (Orgs.). Processos Erosivos no Centro-Oeste Brasileiro. Brasília: FINATEC, 2006. p. 427 464.

VALENTIN, C.; POESEN, J.; LI, Y. Gully erosion: Impacts, factors and control. Catena, v. 63, n. 2-3, p. 132-153, 2005. 